\title{
Computational Methods Applied to Data Analysis for Modeling Complex Real Estate Systems
}

\author{
Marco Locurcio (D), ${ }^{1}$ Francesco Tajani $(D),{ }^{2}$ and Pierluigi Morano ${ }^{1}$ \\ ${ }^{1}$ Department of Civil Engineering Sciences and Architecture, Polytechinic University of Bari, Via Orabona 4, Bari 70125, Italy \\ ${ }^{2}$ Department of Architecture and Design, Sapienza University of Rome, Via Flaminia 359, Rome 00196, Italy \\ Correspondence should be addressed to Marco Locurcio; marco.locurcio@uniroma1.it
}

Received 17 June 2020; Accepted 18 June 2020; Published 9 July 2020

Copyright (c) 2020 Marco Locurcio et al. This is an open access article distributed under the Creative Commons Attribution License, which permits unrestricted use, distribution, and reproduction in any medium, provided the original work is properly cited.

Over the last few decades, as a result of the serious economic and financial crisis that has affected the USA and most European countries, there has been an increasing need for tools that provide reliable mass appraisals. The crisis was triggered by the drastic price reduction of properties as securities for credit exposures, characterized by values that, at the time of the sale due to the debtor's default, had revealed a real market price that made it impossible for the banks to recover the loaned capital.

This contingence has outlined the global connections of the real estate markets and has highlighted, on the one hand, the complex relationship between the real economy and property finance and, on the other hand, the need for multidisciplinary models-e.g., automated valuation ones-that are able to appropriately interpret the available data, identify space-time interactions, and forecast real estate cycles. The complexity of real estate systems concerns the numerous social, economic, and environmental implications that are related to property valuations and regional economic growth, as well as the reciprocal interdependencies between the territorial transformations and their socioeconomic factors.

In this framework, the aim of this Special Issue has been to collate both original research and review articles that contribute to the development of new tools for modeling, optimizing, and simulating complex real estate systems and are related to the applications of data analysis models that take into account the continuous changes of the economic boundary conditions and are able to automatically capture the causal relationships among the variables involved as well as predict property values in the short term.
The main topics of the Special Issue include the following: (i) mass appraisal methods applied to the interpretation of the real estate markets; (ii) multicriteria decision systems as support for valuations in uncertain contexts; (iii) big data analysis for modeling and control approaches; (iv) econometric analysis for the forecasting of real estate trends; (v) GIS-based systems for the identification of spatial correlations among real estate factors; (vi) artificial intelligence implemented for the automated valuation model; (vii) genetic algorithms for the investigation of complex real estate systems.

A total of twenty-one papers were submitted. Following a rigorous procedure of peer review, only seven papers were accepted and published. The different countries of the authors' affiliation (China, Turkey, Portugal, Spain, Italy, and so on) had given the Special Issue a strongly international character.

The paper by S. Chen et al. entitled "GIS-Based Spatial Autocorrelation Analysis of Housing Prices Oriented towards a View of Spatiotemporal Homogeneity and Nonstationarity: A Case Study of Guangzhou, China" describes the housing markets of the city of Guangzhou (China). Through an empirical analysis with the using of traditional regressive models and GIS-based spatial autocorrelation tools, the authors characterize the spatial homogeneity and nonstationarity of the housing prices in the period 2009-2015 with reference to the context of the neighborhoods in Guangzhou. The average annual housing price (AAHP) is the dependent variable, as a function of twelve explanatory variables related to the geographical location 
condition, the transportation accessibility, the commercial service intensity, and the public service intensity. The results outline that (1) the temporal and spatial evolution of the AAHP in Guangzhou shows the circle characteristic with the center of the urban core; (2) there are spatial differences in the growth of AAHP in Guangzhou, which is closely related to the urban planning and the spatial pattern of the urban functional area; (3) the global spatial autocorrelation analysis reveals that the housing price has significant spatial aggregation; (4) the analysis of the linear regression model illustrates the role of the urban infrastructure; (5) the factor of geographical location presents the extreme significant impact on the housing price; (6) the analysis based on the geographically weighted regression model points out the specific effect of each factor on the spatial heterogeneity and nonstationarity of the housing price. The outputs of this study could be a valid support for governing policies and spatial controlling mechanisms of housing markets.

The paper by Y. Chen et al. entitled "Efficiency of Chinese Real Estate Market Based on Complexity-Entropy Binary Causal Plane Method" analyzes the mechanism of house price formation, assuming that the price is a function of the rental income and the average annual household income. The authors implement the complexity-entropy binary causal plane method to detect the hidden structure of real estate market price and then measure its efficiency and complexity. By comparing the applications to Chinese and American contexts, some considerations are derived to define possible guidelines for reducing the information asymmetry in the market and elaborating more detailed rules to help information disclosure in the process of real estate transactions, so as to guarantee the liquidity, accuracy, and timeliness of the information data.

The paper by C. Ç. Dönmez and A. Atalan entitled "Developing Statistical Optimization Models for Urban Competitiveness Index: Under the Boundaries of Econophysics Approach" aims to elaborate a specific urban competitiveness index (UCI) by using the statistical optimization method for the econophysics approach. L'UCI is defined as a combination of the gross domestic product of urban and the gross domestic product per capita of urban with other factors (education, health, and training, labor and transport, technology and industry, market size, product efficiency, and financial service). The complexity of the developed model is attested by the number of indicators that represent the considered factors: totally, thirty-eight indicators have been specified, useful to characterize the complex structure of the urban areas. Borrowing the goal programming logic, the proposed model is applied to thirty cities located in fifteen countries worldwide. The outputs allow identifying the most attractive cities for institutional investors, by considering possible variations of the different factors.

The paper by M. Castelli et al. entitled "Predicting Days on Market to Optimize Real Estate Sales Strategy" develops a model for limiting the problem of irregularities and frauds that are frequent in the real estate market. Starting from the real estate market in Bulgaria, the authors outline that agencies frequently advertise unreal or unavailable apartment listings for a cheap price, as a method to attract unaware potential new customers. According to the authors, the absence of rigorous laws that regulate the real estate market and the duplication of the real estate listings on different advertising portals have increased the need of appropriate transparency. Therefore, the authors present a systematical approach based on data analysis techniques and machine learning methods aimed at identifying frauds in real estate advertisements and improving the transparency of the property listings.

The paper by J.-L. Alfaro-Navarro et al. entitled "A Fully Automated Adjustment of Ensemble Methods in Machine Learning for Modeling Complex Real Estate Systems" proposes an Automated Valuation Model (AVM) to carry out the assessment of real estate prices for an entire country. The authors point out the growing importance of real estate valuations, also highlighted by the close relationship among the collateral value and the bank stability. Starting from a database of about 800,000 properties located in 433 cities in Spain, the AVM is differentiated (based on bagging, boosting, and random forest) for each municipality. The outputs outline that the ensemble methods usually provide good prediction results, although they tend to sacrifice the possible interpretation of the relationships between the predictor variables and the target.

The paper by K. Zhang et al. entitled "Grey Spectrum Analysis of Air Quality Index and Housing Price in Handan" assesses the relationship between an air quality index (AQI) and the housing prices in order to define appropriate guidelines for government programs aimed at reducing the air pollution and regulating the property market. The temporal analysis, based on the grey system theory, is referred to the city of Handan (China) in southern Hebei Province. The application shows that there is a negative correlation between AQI and the housing price; furthermore, due to the specific Chinese policies, the housing prices are gradually stabilizing and the air quality tends to improve.

The paper by E. Allodi et al. entitled "Real Estate Asset Management Companies' Economies of Scale: Is It a Dream or Reality? The Italian Case" aims to verify the presence (or absence) of economies of scale of Italian real estate management companies. The authors highlight that operations of mergers and acquisitions have consolidated the real estate asset management companies, with a consequent increase in the company size. Through a multivariate analysis, the study concerns twenty-six asset management companies, characterized by a total asset under management (AUM) equal to seventy billion euros, i.e., corresponding to $85 \%$ of the total AUM managed by all real estate asset management companies operating in Italy. The implementation of a series of multivariate regressions outlines the absence of relationships that would suggest economies of scale.

All the papers submitted in this Special Issue have demonstrated the current, widespread, and increasing interest of the scientific and professional operators for the implementation of innovative mass appraisal models. In particular, the Special Issue is part of the broader international debate on the contribution that data mining has on the global economy, in accordance with the guidelines of the 
European Coordinated Plan on Artificial Intelligence, and how this typology of models can support to interpret the complexity of real estate dynamics.

\section{Conflicts of Interest}

The lead guest editor and the guest editors declare that there are no conflicts of interest or agreements with private companies, which will prevent them working impartially in the editorial process.

\section{Acknowledgments}

The editors thank all the authors for their contributions.

Marco Locurcio

Francesco Tajani

Pierluigi Morano 